\title{
Diffusion-Weighted Imaging-Detected Ischemic Lesions following Endovascular Treatment of Cerebral Aneurysms: A Systematic Review and Meta-Analysis
}

\author{
(D).M. Bond, (DW. Brinjikji, (D) M.H. Murad, DD.F. Kallmes, DH.J. Cloft, and (D) G. Lanzino
}

\begin{abstract}
BACKGROUND AND PURPOSE: Endovascular treatment of intracranial aneurysms is associated with the risk of thromboembolic ischemic complications. Many of these events are asymptomatic and identified only on diffusion-weighted imaging. We performed a systematic review and meta-analysis to study the incidence of DWI positive for thromboembolic events following endovascular treatment of intracranial aneurysms.
\end{abstract}

MATERIALS AND METHODS: A comprehensive literature search identified studies published between 2000 and April 2016 that reported postprocedural DWI findings in patients undergoing endovascular treatment of intracranial aneurysms. The primary outcome was the incidence of DWI positive for thromboembolic events. We examined outcomes by treatment type, sex, and aneurysm characteristics. Meta-analyses were performed by using a random-effects model.

RESULTS: Twenty-two studies with 2148 patients and 2268 aneurysms were included. The overall incidence of DWI positive for thromboembolic events following endovascular treatment was $49 \%$ ( $95 \% \mathrm{Cl}, 42 \%-56 \%)$. Treatment with flow diversion trended toward a higher rate of DWI positive for lesions than coiling alone (67\%; $95 \% \mathrm{Cl}, 46 \%-85 \%$; versus $45 \%$; $95 \% \mathrm{Cl}, 33 \%-56 \% ; P=.07)$. There was no difference between patients treated with coiling alone and those treated with balloon-assisted $(44 \% ; 95 \% \mathrm{Cl}, 29 \%-60 \% ; P=.99)$ or stent-assisted $(43 \% ; 95 \% \mathrm{Cl}, 24 \%-63 \% ; P=.89)$ coiling. Sex, aneurysm rupture status, location, and size were not associated with the rate of DWI positive for lesions.

CONCLUSIONS: One in 2 patients may have infarcts on DWI following endovascular treatment of intracranial aneurysms. There is a trend toward a higher incidence of DWI-positive lesions following treatment with flow diversion compared with coiling. Patient demographics and aneurysm characteristics were not associated with DWI-positive thromboembolic events.

C il embolization and flow diversion have proved highly efficacious options for the endovascular treatment of intracranial aneurysms. However, both techniques are associated with potential periprocedural complications, including aneurysm rupture, transient ischemic attacks, and ischemic stroke. Small, silent infarcts caused by thromboemboli are often seen on postprocedural diffusion-weighted imaging. While many of these lesions remain ostensibly asymptomatic, the long-term effects of such tiny infarcts remain unclear. ${ }^{1-3}$

Previous studies have reported that the rate of ischemic lesions on postoperative DWI ranges from $10 \%$ to $77 \%$ following coil

Received May 18, 2016; accepted September 6.

From the Mayo Medical School (K.M.B.), Department of Radiology (W.B., D.F.K., H.J.C.), Center for Science of Healthcare Delivery (M.H.M.), and Department of Neurologic Surgery (G.L.), Mayo Clinic, Rochester, Minnesota.

Please address correspondence to Waleed Brinjikji, MD, Mayo Clinic, Department of Radiology, 200 1st St SW, Rochester, MN 55905; e-mail: brinjikji.waleed@mayo.edu; @WBrinjikji

http://dx.doi.org/10.3174/ajnr.A4989

embolization $^{4-15}$ and $51 \%$ to $63 \%$ following therapy with flow diversion. ${ }^{16-19}$ However, baseline clinical and angiographic risk factors for postoperative DWI lesions, to our knowledge, have not been fully elucidated previously. We performed a systematic review and meta-analysis for the following: 1 ) to determine the overall incidence of perioperative infarcts on DWI in patients undergoing endovascular treatment of intracranial aneurysms; and 2) to demonstrate the relationship between treatment type, patient demographics, and aneurysm characteristics with postoperative infarcts on DWI.

\section{MATERIALS AND METHODS}

\section{Literature Search and Inclusion Criteria}

This systematic review and meta-analysis are reported in accordance with the Preferred Reporting Items for Systematic Reviews and Meta-Analysis (PRISMA; http://www.bmj.com/content/339/ bmj.b2535) guidelines. An experienced librarian conducted a comprehensive literature search of PubMed, Ovid MEDLINE, and Ovid EMBASE with input from the authors. The search was 


\begin{tabular}{|c|c|c|c|c|c|c|c|c|c|c|c|c|c|}
\hline \multirow[b]{2}{*}{ Study } & \multirow[b]{2}{*}{ Design } & \multirow{2}{*}{$\begin{array}{l}\text { No. of } \\
\text { Patients }\end{array}$} & \multirow{2}{*}{$\begin{array}{l}\text { Mean } \\
\text { Age }\end{array}$} & \multicolumn{2}{|c|}{ Sex } & \multicolumn{3}{|c|}{ Aneurysms } & \multicolumn{2}{|c|}{ Circulation } & \multirow[b]{2}{*}{ Treatment } & \multirow{2}{*}{$\begin{array}{l}\text { Time until } \\
\text { Imaging (hr) }\end{array}$} & \multirow{2}{*}{$\begin{array}{c}\text { Risk } \\
\text { of } \\
\text { Bias }\end{array}$} \\
\hline & & & & M & $\mathbf{F}$ & Ruptured & Unruptured & Total & Anterior & Posterior & & & \\
\hline Altay et al, $2011^{12}$ & $\mathrm{R}$ & 184 & 58.8 & 44 & $154^{a}$ & 65 & 133 & 198 & 147 & 51 & C, SAC, BAC & $<72$ & $M$ \\
\hline Biondi et al, $2000^{25}$ & $\mathrm{R}$ & 20 & 50 & 5 & 15 & 11 & 9 & 20 & 16 & 4 & $\mathrm{C}$ & $2-4$ and $24-48$ & $M$ \\
\hline Brasiliense et al, $2016^{16}$ & $P$ & 59 & 59 & 11 & 48 & 70 & 0 & 70 & 60 & 10 & FD & 24 & $M$ \\
\hline Cronqvist et al, $2005^{32}$ & $P$ & 40 & 49.4 & 13 & 27 & 16 & 30 & 46 & 38 & 8 & C & $18-52$ & M \\
\hline Hahnemann et al, $2014^{7}$ & $\mathrm{R}$ & 75 & 52.6 & 21 & 54 & 0 & 75 & 75 & 35 & 40 & SAC & $<120$ & $\mathrm{H}$ \\
\hline Heller et al, $2013^{17}$ & $P$ & 76 & 56 & 11 & 65 & 68 & 10 & 78 & 53 & 25 & SAC & $24-48$ & $\mathrm{H}$ \\
\hline losif et al, $2015^{18}$ & $P$ & 38 & 53 & 7 & 31 & - & - & 49 & 48 & 1 & FD & $<48$ & $\mathrm{H}$ \\
\hline Ishibashi et al, $2006^{15}$ & $\mathrm{R}$ & 74 & - & - & - & 29 & 45 & 74 & 63 & 11 & C, BAC & $<48$ & $\mathrm{H}$ \\
\hline Kang et al, $2013^{6}$ & $\mathrm{R}$ & 343 & - & 99 & $283^{a}$ & 0 & 382 & 382 & 323 & 59 & C, SAC, BAC & - & M \\
\hline Kang et al, $2013^{24}$ & $\mathrm{P}$ & 40 & 54.8 & 13 & 27 & 0 & 40 & 40 & 33 & 7 & C, SAC & $<24$ & M \\
\hline Kim et al, $2013^{11}$ & $\mathrm{R}$ & 90 & 58 & 20 & $72^{\mathrm{a}}$ & 0 & 92 & 92 & 78 & 14 & C & $<24$ & M \\
\hline Kim et al, $2014^{10}$ & $\mathrm{R}$ & 58 & - & 23 & 35 & 0 & 62 & 62 & - & - & C, SAC & $23-46$ & M \\
\hline Kim et al, $2016^{27}$ & $R$ & 309 & - & 84 & 225 & 0 & 338 & 338 & 306 & 32 & C, SAC & $24-48$ & $M$ \\
\hline McGuinness et al, $2015^{33}$ & $P$ & 31 & 56 & 4 & 27 & 8 & 25 & 33 & 30 & 3 & FD & $48-240$ & $\mathrm{H}$ \\
\hline Nagahata et al, $2011^{34}$ & $\mathrm{R}$ & 14 & 58.6 & 1 & 13 & 0 & 14 & 14 & 14 & 0 & C, BAC & $<96$ & M \\
\hline Nishikawa et al, $2013^{4}$ & $R$ & 154 & 58.8 & 37 & 117 & 0 & 157 & 157 & 108 & 49 & C, SAC, BAC & $48-120$ & $M$ \\
\hline Park et al, $2016^{5}$ & R & 271 & 57.2 & 68 & 203 & 0 & 271 & 271 & 226 & 45 & C, SAC, BAC & 24 & L \\
\hline Rordorf et al, $2001^{9}$ & $P$ & 14 & 57.2 & 4 & 10 & 0 & 14 & 14 & 14 & 0 & $\mathrm{C}, \mathrm{BAC}$ & $<48$ & M \\
\hline Sim and Shin, $2012^{8}$ & $P$ & 39 & 57.7 & 11 & 28 & 26 & 13 & 39 & 32 & 7 & C, SAC, BAC & $<48$ & $M$ \\
\hline Soeda et al, $2003^{13}$ & $\mathrm{R}$ & 26 & 60 & 8 & 18 & 0 & 26 & 26 & 0 & 26 & $\mathrm{C}, \mathrm{BAC}$ & $48-120$ & M \\
\hline Takigawa et al, $2014^{14}$ & $\mathrm{R}$ & 119 & 62.9 & 30 & 89 & 0 & 119 & 119 & 95 & 24 & SAC, BAC & 24 & M \\
\hline Tan et al, $2015^{19}$ & $\mathrm{R}$ & 74 & 60 & 12 & 62 & 0 & 74 & 74 & 58 & 16 & FD & $<24$ & M \\
\hline
\end{tabular}

Note:-R indicates retrospective; P, prospective; C, coiling only; SAC, stent-assisted coiling; BAC, balloon-assisted coiling; FD, flow diversion; $H$, high; M, moderate; L, low; -, data was not available.

${ }^{\text {a }}$ Authors reported sex distribution by number of aneurysms.

performed by using the following keywords: "coiling," "pipeline," "flow diverter," "aneurysm," "endovascular," "diffusion," "restricted diffusion," "MR imaging," and "stroke" in both "AND" and "OR" combinations. The search was limited to English articles published from 2000 to April 2016. The inclusion criteria were the following: 1) consecutive series of $\geq 10$ patients who underwent endovascular treatment of intracranial aneurysms with endosaccular coiling or flow diversion, and 2) DWI examination performed within 5 days of endovascular treatment in all patients. Exclusion criteria were the following: 1) $<10$ patients in the series, 2) series that reported outcomes of parent artery occlusion, 3) studies in which only symptomatic patients underwent postoperative DWI imaging, 4) studies that did not provide the number of patients who had no lesions on DWI, and 5) studies for which an English translation was not available. Two independent reviewers determined whether the articles met the inclusion and exclusion criteria for this systematic review and meta-analysis. The following baseline information was extracted from each study: number of patients, mean age, sex distribution, mean aneurysm size, aneurysm location, and rupture status.

\section{Outcomes and Patient Groups}

The primary outcome of this study was the overall rate of DWI positive for thromboembolic events following endovascular aneurysm treatment. We also performed subgroup analyses stratified by treatment type (ie, coiling, stent-assisted coiling, balloonassisted coiling, and flow diversion), patient sex (male versus female), aneurysm size (small versus large/giant), aneurysm location (anterior versus posterior circulation), and aneurysm rupture status (ruptured versus unruptured). Small aneurysms were defined as those with a maximum diameter of $<10 \mathrm{~mm}$.

\section{Risk of Bias Assessment}

We selected items from the Newcastle-Ottawa Scale for nonrandomized trials to fit the type of included studies. We queried the following study characteristics: 1) patient groups clearly defined, 2) outcomes clearly reported, 3) outcomes clearly reported for each patient group studied, 4) imaging interpreted by an independent reader or interpreted by the operator, 5 ) readers blinded to the clinical status of the patient, 6) multiple readers used and interobserver agreement assessed, and 7) the study followed a predefined study protocol in which all patients underwent MR imaging at the same time point.

\section{Statistical Analysis}

We estimated from each study the cumulative incidence (event rate at the end of the study) and $95 \%$ confidence interval. Because we anticipated marked heterogeneity in the populations and interventions across the various included studies, a random-effects model was used to pool incident rates across studies. ${ }^{20}$ Variance was estimated by using the Freeman-Tukey Double Arcsine Transformation. ${ }^{21,22}$ The $\mathrm{I}^{2}$ statistic was used to express the proportion of inconsistency that is not attributable to chance. ${ }^{23}$ Analysis was conducted by using the STATA Statistical Software for 2015: Release 14 (StataCorp, College Station, Texas).

\section{RESULTS}

\section{Search Results and Patient Population}

The literature search yielded 533 records, of which 424 were deemed irrelevant by reading the title and abstract alone. Of the remaining 109 records, 45 were duplicates, abstracts only, or review articles. Forty-two did not meet our minimum sample size criterion of $\geq 10$ patients or did not provide data for the number 


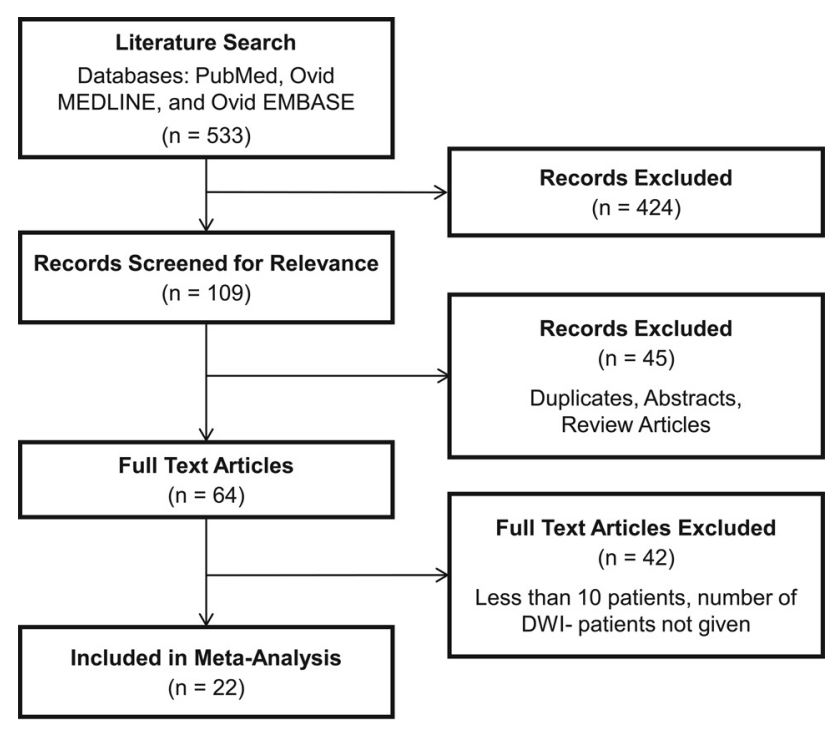

FIG 1. Flow chart illustrating study selection.

Table 2: Incidence of ischemic strokes as measured by restricted diffusion with DWI

\begin{tabular}{lccc}
\hline & \% DWI+ (95\% CI) & $\mathbf{I}^{2}$ & $P$ Value \\
\hline Overall & $49(42-56)$ & 90 & - \\
Location & $35(25-47)$ & 76 & .83 \\
$\quad$ Anterior & $31(9-59)$ & 87 & \\
$\quad$ Posterior & & & \\
Treatment type & $45(33-56)$ & 86 & Ref \\
$\quad$ Coiling alone & $44(29-60)$ & 54 & .99 \\
$\quad$ Balloon-assisted coiling & $43(24-63)$ & 93 & .89 \\
$\quad$ Stent-assisted coiling & $67(46-85)$ & 87 & .07 \\
$\quad$ Flow diversion & & & \\
Sex & $32(17-48)$ & 58 & .47 \\
$\quad$ Male & $41(28-54)$ & 84 & \\
$\quad$ Female & & & \\
Rupture status & $42(17-69)$ & 90 & .87 \\
$\quad$ Ruptured & $44(35-53)$ & 87 & \\
$\quad$ Unruptured & & & \\
Size & & \\
$\quad$ Small & $52(39-65)$ & 62 & .55 \\
$\quad$ Large & $61(34-86)$ & 38 & \\
\hline
\end{tabular}

Note:-Ref indicates reference.

of patients with no DWI positive for lesions. Twenty-two studies met all of our inclusion criteria and were included in the metaanalysis. A summary of these studies is provided in Table 1. The PRISMA flow diagram is provided in Fig 1.

In total, 2148 patients with 2268 aneurysms were included in this study. Five hundred ninety-two aneurysms were treated with coiling alone; 376, with stent-assisted coiling; 162, with balloonassisted coiling; and 178, with flow diversion. Two hundred ninety-two aneurysms had ruptured at the time of treatment, while 1927 aneurysms remained unruptured. Four hundred thirtysix aneurysms were located in the anterior circulation, and 129 were in the posterior circulation.

\section{Study Outcomes}

The rates of postprocedural DWI positive for thromboembolic events are summarized in Table 2. Overall, $49 \%$ of all patients had DWI positive for lesions following endovascular treatment of cerebral aneurysms (95\% CI, 42\%-56\%) (Fig 2). The rate of infarcts in patients treated with simple coiling was 45\% (95\% CI, 33\%-56\%). This was no different from those treated with balloon-assisted coiling (44\%; 95\% CI, 29\%-60\%; $P=.99$ ) or stent-assisted coiling (43\%; $95 \% \mathrm{CI}, 24 \%-63 \% ; P=.89$ ). The rate of DWI positive for lesions in patients treated with flow diversion was $67 \%$ and approached statistical significance (95\% CI, 46\%-85\%; $P=.07$ ) (Fig 3).

Patient sex was not associated with the rate of DWI positive for lesions because $32 \%$ (95\% CI, 17\%-48\%) of men and $41 \%$ (95\% CI, $28 \%-54 \%)$ of women had postoperative infarcts $(P=.47)$. In comparing aneurysm size, the rate of DWI positive for thromboembolic events was 52\% (95\% CI, 39\%-65\%) for small aneurysms and $61 \%(95 \% \mathrm{CI}, 34 \%-86 \%)$ for large aneurysms $(P=$ .55). The rate of infarcts was not different between patients with aneurysms in the anterior circulation (35\%; 95\% CI, 25\%-47\%) and posterior circulation $(31 \%$; $95 \% \mathrm{CI}, 9 \%-59 \% ; P=.83)$. Aneurysm rupture status was not associated with the rate of stroke because $42 \%$ (95\% CI, 17\%-69\%) of patients with ruptured aneurysms and $44 \%(95 \%$ CI, 35\%-53\%; $P=.87)$ of those with unruptured aneurysms had DWI positive for lesions.

\section{Study Heterogeneity and Risk of Bias}

$\mathrm{I}^{2}$ values were $>50 \%$ for all outcomes, with the exception of postoperative infarct rate for large aneurysms, indicating substantial heterogeneity. Of the 22 studies included in this meta-analysis, 14 were retrospective and 8 were prospective. Five studies had a high risk of bias, 16 studies had a moderate risk of bias, and 1 study had a low risk of bias as determined by our modified NewcastleOttawa Scale criterion.

\section{DISCUSSION}

This systematic review and meta-analysis demonstrated that the overall incidence of DWI positive for thromboembolic events following endovascular treatment of intracranial aneurysms is approximately $50 \%$, with no significant difference between coiling with and without adjunct devices. In addition, there was no association between postoperative DWI positive for lesions and patient sex or aneurysm location, size, or rupture status. There was a trend toward a higher infarct rate among patients treated with flow diversion compared with traditional endovascular coiling techniques; however, this did not reach statistical significance. Because these so-called "clinically silent strokes" have been associated with cognitive decline, depression, and future stroke, these findings highlight the importance of finding new techniques aimed at reducing perioperative infarcts. ${ }^{1-3,24}$

Several studies have identified risk factors for both symptomatic and asymptomatic lesions positive on DWI following treatment with traditional endovascular techniques. These include large aneurysm size, female sex, age, atherosclerotic disease, and protruding loops of coil..$^{8,13,25,26}$ Some studies have found that balloon-assisted and stent-assisted coiling increased the risk of thromboembolic complications, while others found no association. ${ }^{5,6,8-10,13-15,27}$ In contrast, our large study demonstrates that no anatomic or demographic risk factors are associated with this particular postoperative complication. Prior studies have demonstrated that aggressive antiplatelet and anticoagulation therapy is also associated with a reduction in perioperative ischemic 


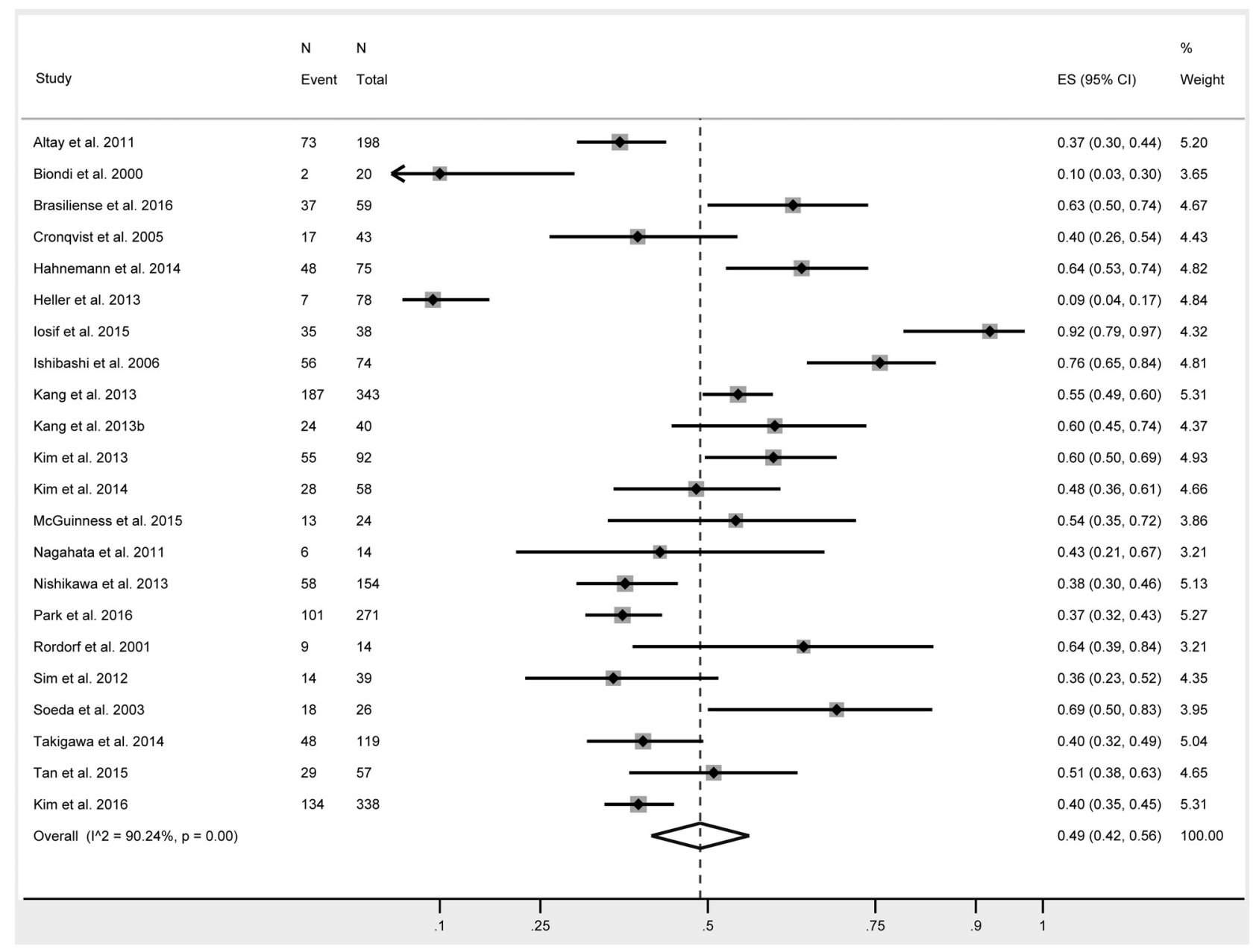

FIG 2. Forest plot demonstrating the overall rate of silent infarcts following endovascular aneurysm treatment.

events, ${ }^{28}$ but our meta-analysis did not consider this parameter because it was inconsistently reported by the included studies.

One of the interesting findings from our meta-analysis was the trend toward a higher rate of silent infarcts in patients treated with flow diverters compared with those treated with coils alone. While both coils and flow diverters are inherently thrombogenic, treatment with flow diversion is generally associated with a higher rate of thromboembolic complications than with coiling alone. ${ }^{19} \mathrm{Be}-$ cause flow diverters are high-density metal constructs with large endoluminal surface areas, these devices pose a higher risk of thrombosis in the lumen of the parent artery. Shearing stress from blood flow through the device can cause these thrombi to embolize. In contrast, thrombi that form on lower density coils are less likely to embolize into the bloodstream because of the placement of the coil in the aneurysm sac outside the cerebral circulation. ${ }^{29}$

The high rate of asymptomatic DWI positive for lesions raises questions about the clinical relevance of these tiny strokes. Most thromboembolic events likely do not present as focal neurologic deficits simply because they occur in noneloquent locations. However, many of these so-called "clinically silent" lesions may actually give rise to nongross neurologic deficits. Thus, studies have prospectively explored the relationship between DWI positive for lesions and neuropsychological examination performance and have yielded variable results. Studies from the cardiac litera- ture have found that patients with DWI lesions post-cardiac endovascular and surgical procedures have reduced cognitive function on neuropsychological examinations. ${ }^{30,31}$ However, studies from the coiling and flow-diversion literature have demonstrated no association between the presence of DWI lesions and neuropsychological examination performance. ${ }^{24,18}$ Given these conflicting results, the relevance of DWI positive for lesions to cognitive function remains uncertain, and further study is needed to evaluate the long-term consequences of these infarcts.

\section{Limitations}

Our study has several limitations. Many of the studies included in our analysis were retrospective, noncomparative, and nonrandomized. There was substantial variability in methods and the detail in which outcomes were reported. For example, the type of antiplatelet therapy and the time elapsed between the procedures and imaging were inconsistent between studies. Additionally, many articles gave an incomplete account of patient demographics, symptomatic status, and neurologic outcomes. Our study also has publication bias, and we acknowledge the methodologic differences between institutions and the tendency for retrospective studies to only publish positive results. We did not compare outcomes based on the type of anticoagulation and antiplatelet therapy, a parameter that likely influences clot formation and isch- 


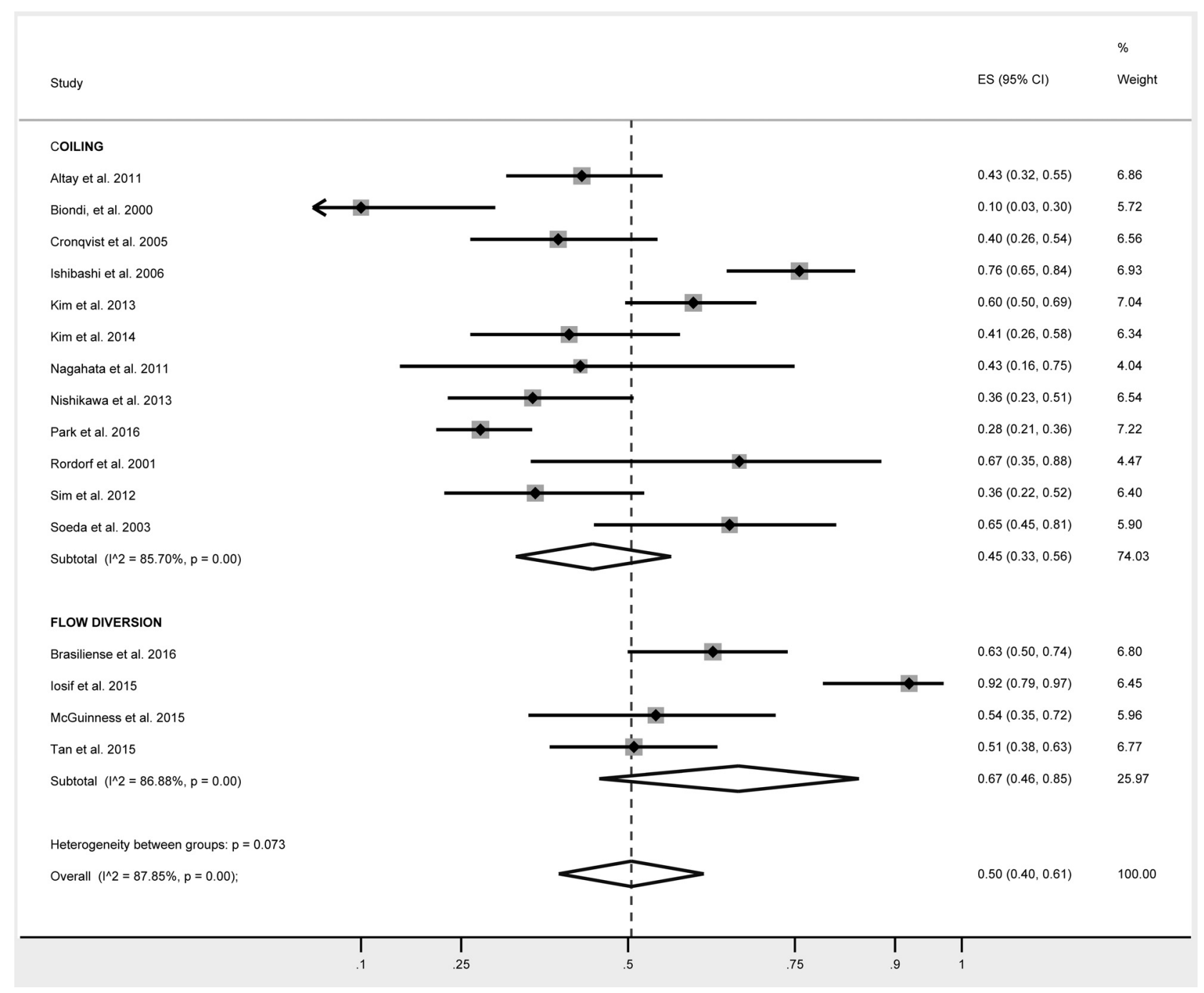

FIG 3. Forest plot demonstrating the overall rate of silent infarcts following treatment with coiling and flow diversion.

emic stroke incidence. Similarly, we did not consider the lesion load of each patient and the relationship of this value to predicting symptoms. MR imaging techniques likely differ from institution to institution. It is possible that differences in MR imaging field strength, B0 values, and section thickness affect the overall rate of DWI lesion detection. It is important to consider these limitations when interpreting the results of this meta-analysis.

\section{CONCLUSIONS}

Our meta-analysis, which included $>2000$ patients undergoing endovascular treatment of intracranial aneurysms, demonstrated that the overall rate of postoperative DWI positive for thromboembolic events is approximately 50\%, with no differences when comparing coiling techniques, aneurysm characteristics, or patient sex. There was a trend toward a higher rate of thromboembolic complications among those treated with flow diverters compared with those treated with coiling alone. Because the long-term effects of these so-called silent infarcts are unclear, further work is needed to develop techniques to reduce the rate of thromboembolic complications associated with endovascular aneurysm treat- ment. Given the limitations of this meta-analysis, prospective studies with uniform methods are needed to confirm these results.

Disclosures: David F. Kallmes—UNRELATED: Board Membership: GE Healthcare, Comments: Cost-Effectiveness Board*; Consultancy: Medtronic, Minnetronix, Comments: planning clinical trials, Data and Safety Monitoring Board Chair*; Grants/ Grants Pending: MicroVention, Medtronic, SurModics, Sequent, NeuroSigma, Codman, Comments: clinical trials and preclinical research*; Travel/Accommodations/ Meeting Expenses Unrelated to Activities Listed: Medtronic, Comments: presentation at an FDA panel meeting. ${ }^{*}$ Giuseppe Lanzino-UNRELATED: Consultancy: Covidien/Medtronic.* *Money paid to the institution.

\section{REFERENCES}

1. Kang DW, Lattimore SU, Latour LL, et al. Silent ischemic lesion recurrence on magnetic resonance imaging predicts subsequent clinical vascular events. Arch Neurol 2006;63:1730-33 CrossRef Medline

2. Vermeer SE, Prins ND, den Heijer T, et al. Silent brain infarcts and the risk of dementia and cognitive decline. N Engl J Med 2003;348: 1215-22 CrossRef Medline

3. Choi SH, Na DL, Chung CS, et al. Diffusion-weighted MRI in vascular dementia. Neurology 2000;54:83-89 CrossRef Medline

4. Nishikawa $Y$, Satow T, Takagi T, et al. Efficacy and safety of single 
versus dual antiplatelet therapy for coiling of unruptured aneurysms. J Stroke Cerebrovasc Dis 2013;22:650-55 CrossRef Medline

5. Park JC, Lee DH, Kim JK, et al. Microembolism after endovascular coiling of unruptured cerebral aneurysms: incidence and risk factors. J Neurosurg 2016;124:777-83 CrossRef Medline

6. Kang DH, Kim BM, Kim DJ, et al. MR-DWI-positive lesions and symptomatic ischemic complications after coiling of unruptured intracranial aneurysms. Stroke 2013;44:789-91 CrossRef Medline

7. Hahnemann ML, Ringelstein A, Sandalcioglu IE, et al. Silent embolism after stent-assisted coiling of cerebral aneurysms: diffusionweighted MRI study of 75 cases. J Neurointerv Surg 2014;6:461-65 CrossRef Medline

8. Sim SY, Shin YS. Silent microembolism on diffusion-weighted MRI after coil embolization of cerebral aneurysms. Neurointervention 2012;7:77-84 CrossRef Medline

9. Rordorf G, Bellon RJ, Budzik RF Jr, et al. Silent thromboembolic events associated with the treatment of unruptured cerebral aneurysms by use of Guglielmi detachable coils: prospective study applying diffusion-weighted imaging. AJNR Am J Neuroradiol 2001; 22:5-10 Medline

10. Kim B, Kim K, Jeon P, et al. Thromboembolic complications in patients with clopidogrel resistance after coil embolization for unruptured intracranial aneurysms. AJNR Am J Neuroradiol 2014;35: 1786-92 CrossRef Medline

11. Kim MJ, Lim YC, Oh SY, et al. Thromboembolic events associated with electrolytic detachment of Guglielmi detachable coils and target coils: comparison with use of diffusion-weighted MR imaging. J Korean Neurosurg Soc 2013;54:19-24 CrossRef Medline

12. Altay T, Kang HI, Woo HH, et al. Thromboembolic events associated with endovascular treatment of cerebral aneurysms. J Neurointerv Surg 2011;3:147-50 CrossRef Medline

13. Soeda A, Sakai N, Murao K, et al. Thromboembolic events associated with Guglielmi detachable coil embolization with use of diffusion-weighted MR imaging, part II: detection of the microemboli proximal to cerebral aneurysm. AJNR Am J Neuroradiol 2003;24: 2035-38 Medline

14. Takigawa T, Suzuki K, Sugiura Y, et al. Thromboembolic events associated with single balloon-, double balloon-, and stent-assisted coil embolization of asymptomatic unruptured cerebral aneurysms: evaluation with diffusion-weighted MR imaging. Neuroradiology 2014;56: 1079-86 CrossRef Medline

15. Ishibashi T, Murayama Y, Saguchi T, et al. Thromboembolic events during endovascular coil embolization of cerebral aneurysms. Interv Neuroradiol 2006;12:112-16 Medline

16. Brasiliense LB, Stanley MA, Grewal SS, et al. Silent ischemic events after Pipeline embolization device: a prospective evaluation with MR diffusion-weighted imaging. J Neurointerv Surg 2016 Jan 8. [Epub ahead of print] Medline

17. Heller RS, Dandamudi V, Calnan D, et al. Neuroform intracranial stenting for aneurysms using simple and multi-stent technique is associated with low risk of magnetic resonance diffusion-weighted imaging lesions. Neurosurgery 2013;73:582-90; discussion 590-91 CrossRef Medline

18. Iosif C, Camilleri Y, Saleme S, et al. Diffusion-weighted imagingdetected ischemic lesions associated with flow-diverting stents in intracranial aneurysms: safety, potential mechanisms, clinical outcome, and concerns. J Neurosurg 2015;122:627-36 CrossRef Medline
19. Tan LA, Keigher KM, Munich SA, et al. Thromboembolic complications with Pipeline Embolization Device placement: impact of procedure time, number of stents and pre-procedure $\mathrm{P} 2 \mathrm{Y} 12$ reaction unit (PRU) value. J Neurointerv Surg 2015;7:217-21 CrossRef Medline

20. DerSimonian R, Laird N. Meta-analysis in clinical trials. Control Clin Trials 1986;7:177-88 CrossRef Medline

21. Barendregt JJ, Doi SA, Lee YY, et al. Meta-analysis of prevalence. J Epidemiol Community Health 2013;67:974-78 CrossRef Medline

22. Freeman MF, Tukey JW. Transformations related to the angular and the square root. The Annals of Mathematical Statistics 1950;21: 607-11 CrossRef

23. Higgins JP, Thompson SG, Deeks JJ, et al. Measuring inconsistency in meta-analyses. BMJ 2003;327:557-60 CrossRef Medline

24. Kang DH, Hwang YH, Kim YS, et al. Cognitive outcome and clinically silent thromboembolic events after coiling of asymptomatic unruptured intracranial aneurysms. Neurosurgery 2013;72:638 -45; discussion 645 CrossRef Medline

25. Biondi A, Oppenheim C, Vivas E, et al. Cerebral aneurysms treated by Guglielmi detachable coils: evaluation with diffusion-weighted MR imaging. AJNR Am J Neuroradiol 2000;21:957-63 Medline

26. Soeda A, Sakai N, Sakai H, et al. Thromboembolic events associated with Guglielmi detachable coil embolization of asymptomatic cerebral aneurysms: evaluation of 66 consecutive cases with use of diffusion-weighted MR imaging. AJNR Am J Neuroradiol 2003;24: 127-32 Medline

27. Kim MS, Jo KI, Yeon JY, et al. Association between postprocedural infarction and antiplatelet drug resistance after coiling for unruptured intracranial aneurysms. AJNR Am J Neuroradiol 2016;37: 1099-105 CrossRef Medline

28. Pelz DM, Lownie SP, Fox AJ. Thromboembolic events associated with the treatment of cerebral aneurysms with Guglielmi detachable coils. AJNR Am J Neuroradiol 1998;19:1541-47 Medline

29. Derdeyn CP, Cross DT 3rd, Moran CJ, et al. Postprocedure ischemic events after treatment of intracranial aneurysms with Guglielmi detachable coils. J Neurosurg 2002;96:837-43 CrossRef Medline

30. Lund C, Nes RB, Ugelstad TP, et al. Cerebral emboli during left heart catheterization may cause acute brain injury. Eur Heart J 2005;26: 1269-75 CrossRef Medline

31. Restrepo L, Wityk RJ, Grega MA, et al. Diffusion- and perfusionweighted magnetic resonance imaging of the brain before and after coronary artery bypass grafting surgery. Stroke 2002;33:2909-15 CrossRef Medline

32. Cronqvist M, Wirestam R, Ramgren B, et al. Diffusion and perfusion MRI in patients with ruptured and unruptured intracranial aneurysms treated by endovascular coiling: complications, procedural results, MR findings and clinical outcome. Neuroradiology 2005;47: 855-73 CrossRef Medline

33. McGuinness BJ, Memon S, Hope JK. Prospective study of early MRI appearances following flow-diverting stent placement for intracranial aneurysms. AJNR Am J Neuroradiol 2015;36:943-48 CrossRef Medline

34. Nagahata M, Kondo R, Saito S, et al. Which factors increase procedural thromboembolic events in patients with unruptured paraclinoid internal carotid artery aneurysm treated by coil embolization? Neuroradiol J 2011;24:712-14 CrossRef Medline 